\title{
A Study of the Impact of Recent Floods on the Micro, Small, and Medium Business Enterprises of Kerala
}

\author{
K. Amal Prakash and S.D. Krishnarani* \\ PG \& Research Department of Statistics, Farook College (Autonomous) (Affiliated to \\ University of Calicut), Kozhikode 673632, Kerala, India
}

Article Type: Article

Article Citation: Amal Prakash K, Krishnarani SD. A study of the impact of recent floods on the micro, small and medium business enterprises of Kerala. Indian Journal of Science and Technology. 2020; 13(06), 686-695. D0l: 10.17485/ijst/2020/v013i06/149831

Received date: January 5, 2020

Accepted date: January 23, 2020

*Author for correspondence: KrishnaraniS.D. krishnaranisd@ gmail.com P PG \& Research Department of Statistics, Farook College (Autonomous) (Affiliated to University of (alicut), Kozhikode 673632, Kerala, India

\begin{abstract}
Objective: To study the impact of Kerala floods of 2018 in the Micro, Small, and Medium Business Enterprises of Kerala. Method/ analysis: The study was conducted with the primary data obtained from the ground response of the entrepreneurs by the method of questionnaire. A comprehensive study was undertaken utilizing the competence of advanced statistical tools and software that provided clear insights on the socio-economic aftermaths of the calamity. Findings: The customer arrival has declined in the flood affected urban areas while rural localities remained same. Purchasing capacity of customers decelerated in the rural localities whereas in urban localities approximate to normal. The expenditure incurred for the entrepreneurs as the result of the devastation was enormously hiked at the same time the employment generation experienced a significant dip in the sector. The overall function of the sector is slowly approaching the normalcy. The rural localities suffered extremely from the disruption of transportation due to extensive damages on roads and highways whereas urban localities have relieved from the disruption of movement of goods. It was found that insurance coverage has not helped them to recover from the losses incurred due to flood. The enterprises functioning in ecologically sensitive areas were the worst affected by the flood. The distribution of income was found to have significant divergence among the urban and rural localities. Applications and improvements: Mandating the inclusion of insurance policy reforms with specific consideration for employment generation and enhancement of rural economy is necessary. Strict implementation of environmental norms should be constituted.
\end{abstract}

Keywords: Micro, Small, and Medium Business Enterprises, Purchasing Capacity, Employability, Movement of Goods, Insurance Fulfilments. 


\section{Introduction}

The state of Kerala was affected by the most cataclysmic floods in its history during the month of August 2018. This natural disaster created a great havoc in the state resulted in extensive vitiation of life and properties. The productive sectors of economy viz-a-viz agriculture, industries, micro-small and medium enterprises (MSMEs), and tourism were the worst affected by the devastations of the flood.

Kerala, being a consumer state depends heavily on MSMEs, which are recognized as the growth engines of the economy, perform a critical role in strengthening the economy by providing employment to a large number of people (including semi-skilled and unskilled workers). They contribute immensely to exports, raising manufacturing sector production and extending support to bigger industries by supplying raw materials, basic goods, finished products and components, etc. It also ensures equitable distribution of national income and facilitates effective mobilization of private sector resources of capital and skills. The recent floods of 2018 have had created a very devastating effect in economic prospects of MSME sector. Hence, by the data collection instrument of questionnaire and personal interaction with entrepreneurs and MSME owners in Kerala this study seeks to understand the socio-economic changes that resulted after the recent floods and landslides.

In India, the enterprises have been classified broadly into two categories [1]:

(i) Manufacturing; and

(ii) Those engaged in providing/rendering of services

Both categories of enterprises have been further classified into micro, small, and medium enterprises based on their investment in plant and machinery (for manufacturing enterprises) or on equipment (in case of enterprises providing or rendering services). The present ceiling on investment to be classified as micro, small, or medium enterprises is as given in Table 1:

TABLE 1. Investment ceiling for plant, machinery or equipments

\begin{tabular}{lll}
\hline Classification & Manufacturing enterprises & Service enterprises \\
\hline Micro & Up to Rs. 25 lakh $(\$ 50$ thousand) & Up to Rs. 10 lakh $(\$ 20$ thousand) \\
Small & Above Rs. 25 lakh $(\$ 50$ thousand) & Above Rs. 10 lakh $(\$ 20$ thousand) \& up to \\
& \& up to Rs.5 crore $(\$ 1$ million) & Rs. 2 crore $(\$ 0.40$ million $)$ \\
Medium & Above Rs. 5 crore $(\$ 1$ million) \& & Above Rs. 2 crore $(\$ 0.40$ million) \& up to \\
& up to Rs. 10 crore $(\$ 2$ million) & Rs. 5 crore $(\$ 1$ million $)$ \\
\hline
\end{tabular}

The recent floods in Kerala have jolted the MSMEs in a great extent. Therefore, a study in this regard is imperative for understanding the ground reality of MSME sector.

\subsection{Objectives}

- To study the impact of flood in MSME sector in a socio-economic perspective.

- To identify the ecological factors that should be taken into consideration in order to reduce the impact of another natural disaster.

- To identify key aspects for the resumption of smooth functioning of the MSME sector. 


\subsection{Scope of the Study}

This article provides a comprehensive study and analysis of various micro economic aspects of MSME sectors together with its social, ecological aftermaths as the result of the devastating floods. It will also provide a clear insight to the ground situation of the MSME sector of Kerala that enables policy makers, government bodies and think tanks to perceive a clear understanding and make informed decisions and policies to heighten the prospects of the sector.

\section{Materials and Methods}

The research was conducted through a questionnaire as the data collection instrument of study. It was structured comprehending various imperative aspects that weigh the intensity and extent of the severity of the recent mishap.

The questionnaire was structured both in English and Malayalam, which helped immensely to get a good deal of information. The extent of the devastation occurred due to the course of flood covers a large area of locality. Since the purpose of this study is to identify the key aspects that constituted a major impact in the MSME sector, the critical areas, which the adverse impact of the flood and landslides, were severely catastrophic were shortlisted based on the newspaper reports and personal inspection. These areas were categorically separated with the intend to find the differences it displays in the urban/rural areas, particularly to observe the micro-economic changes resulted due to the aftermath of the flood [2-3]. A sample of 70 responses was collected from severely affected areas of Kozhikode and Malappuram districts viz Kondotty, Vazhakkad, Azhinjilam, Edavannappara, Pulikkal and was followed by analysis using descriptive statistics, inferential statistics, and various graphs. The statistical tools used for the analysis were Fishers exact test, Mann Whitney test, and Median test. The queries were asked predominantly in the nature of objective type questions in a standardised way, extending as an interview discussing various key aspects. The major variables considered for the study are change in the number of customer arrivals, income level, purchasing capacity, expenditure, insurance, waste disposal methods, etc. The details of the sample data are delineated in Table 2.

TABLE 2. Sample details

\begin{tabular}{lll}
\hline Locality & Number of respondents & Percent \\
\hline Urban & 45 & 64.3 \\
Rural & 25 & 35.7 \\
Total & $\mathbf{7 0}$ & $\mathbf{1 0 0 . 0}$ \\
\hline
\end{tabular}

\section{Results and Discussion}

All the statistical tests and its values coming under this session are given in Table 3. 
TABLE 3. Summary of various tests

\begin{tabular}{lllrc}
\hline Test criterion & Variables & $\begin{array}{l}\text { Statistical } \\
\text { test }\end{array}$ & $\begin{array}{c}\text { Test statistic } \\
\text { value }\end{array}$ & P value \\
\hline Independence of & Impact of flood and locality & Fishers exact & 2.725 & 0.259 \\
& $\begin{array}{l}\text { Customer arrival and locality } \\
\text { Purchasing capacity and locality }\end{array}$ & test & 10.481 & 0.004 \\
& $\begin{array}{l}\text { Expenditure and locality } \\
\text { Production of goods/service }\end{array}$ & 11.225 & 0.034 \\
& $\begin{array}{l}\text { operationalization and locality } \\
\text { Movement of goods and locality }\end{array}$ & 2.293 & 0.008 \\
& $\begin{array}{l}\text { Employment generation and } \\
\text { locality }\end{array}$ & 8.657 & 0.020 \\
& Insurance and recovery & 3.931 & 0.151 \\
Equality & $\begin{array}{l}\text { Distribution of income and } \\
\text { locality }\end{array}$ & Mann- & 9.246 & 0.085 \\
Median & Severity of the damages caused & Whitney $U$ test & - & 0.002 \\
\hline
\end{tabular}

\subsection{Flood Affected Locality and Impact of Flood}

We have 45 data sets from urban and 25 from rural areas. Fishers exact test was done to study the impact of flood in different localities and from the $p$-value of 0.259 , we concluded that the impact of flood is independent of the rural or urban areas. From the study, it was understood that both the urban and rural areas were equally impacted even though the intensity of damages incurred varied with respect to their investment and area of business. But the data reveal that recovery from the losses and damages was faster in rural localities than the urban localities. The manufacturing sector which especially deals with the advanced machinery was immensely suffered by the disaster. It was also noted that topography of which the enterprises were situated influenced the intensity of damage reported. It was evident that permission for the operation of MSMEs in certain sensitive topographical areas needed to be sanctioned with utmost consideration and scrutiny.

\subsection{Flood Affected Locality and Customer Arrival}

The study about the dependence of customer arrival and the localities, Fishers exact test resulted in a $p$ value of 0.004 , confirming that the customer arrival is dependent on the locality. The customer arrival in rural areas approximately continued in the same phase, but the urban areas experienced a significant shortfall in the customer arrivals. Considering the population of the enterprises in the locality, which is less in the rural areas and more in the urban areas; it may or may not depend on the availability of products. It can be also related to the fact that the recovery from the loss incurred was at a faster rate in rural areas may be based on this phenomena, whereas the urban areas lacked behind due to less customer arrival.

\subsection{Flood Affected Locality and Purchasing Capacity}

The locality of the flood affected areas and purchasing capacity of the population residing were studied using Fishers exact test and found dependent since $p$-value was 0.034 . The 
purchasing capacity of customers was observed to have declined significantly immediately after the flood in both urban and rural localities. It resulted in the slowdown of the growth of business that prompted too many adjustments in the sector. The purchasing capacity of the population residing on rural areas was found to continue its deceleration even after 4-5 months after the flood whereas the urban areas is hasting towards normalcy.

\subsection{Flood Affected Locality and Expenditure}

In studying the expenditure incurred on resuming the normalcy after the flood with respect to the rural and urban areas, using Fishers exact test the $p$-value was 0.008 and we reached at the conclusion that locality and expenditure are dependent. The catastrophe of the flood which resulted in a destruction in machinery, electrical equipment, buildings, and other properties have resulted in a huge economic burden for entrepreneurs for reconstruction and revamp of smooth functioning of the sector. It was reflected in the study that flood affected enterprises experienced a significant hike in expenditure in urban areas that destabilized their financial stability. It was also perceived that government assistance given for the MSMEs as a relief measure was not enough to facilitate the restart of the sector. In many instances, red tapes immensely discouraged the investors making many of them depending on loans and debts. This was observed as a major concern among the entrepreneurs and some of the suggestions raised from them were providing low interest loans, increasing the financial assistance extended by the government, reducing the tax/ GST level as explained in Figure 1.

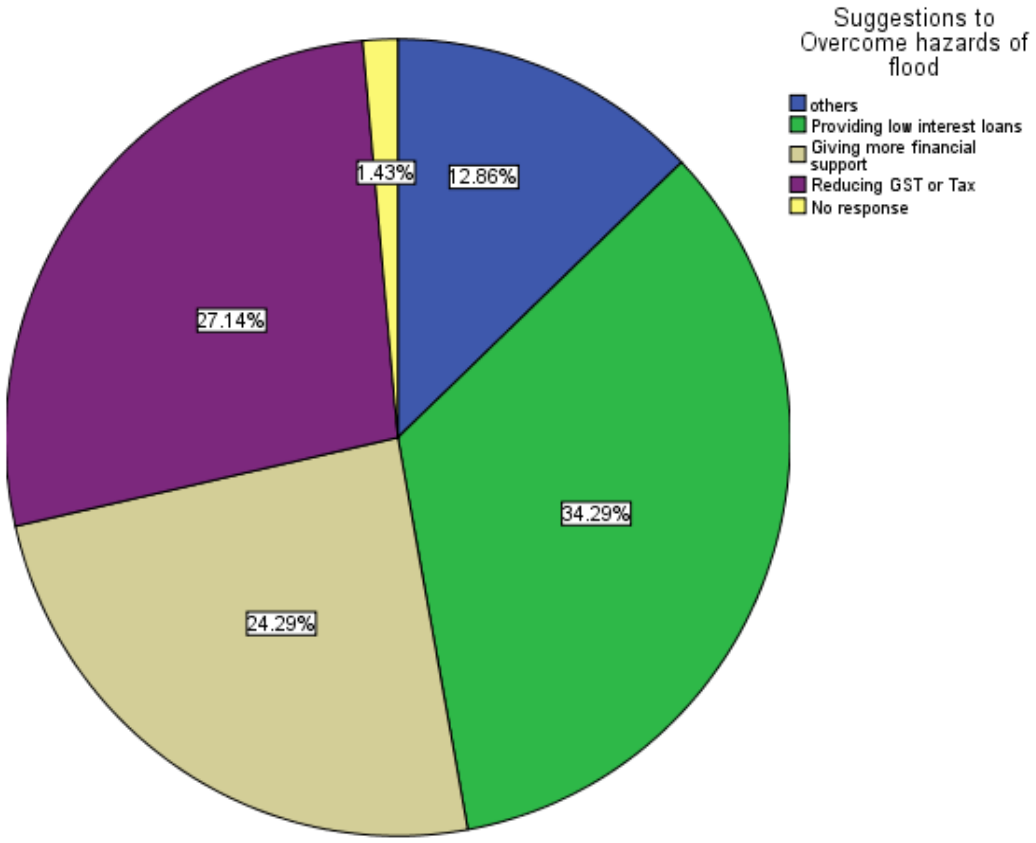

FIGURE 1. Suggestions to overcome hazards of flood. 


\subsection{Flood Affected Locality and Production of Goods/Service Operationalization}

The analysis using Fishers exact test has $p$-value 0.545 and hence locality and production/ service operationalization are independent. MSMEs in the flood affected areas suffered a setback by the heavy devastation but the production of the goods/service operationalization has been slowly getting back to its potential.

\subsection{Locality and Transportation of Goods}

The transportation of goods plays a prominent role in normal functioning of a business. As the result of the recent floods, the movement of goods (to and fro) was in a total jeopardy immediately after the floods. Due to the decisive action of the public works department and other authorities, the transportation is slowly approaching the normalcy. But in severely devastated localities transportation facilities are found to be a real challenge for the enterprises. Statistical evidence with $p$ value 0.02 for the Fishers exact test confirms that the transportation of goods is associated with the locality. It was evident from the study that the rural localities suffered extremely from the disruption of transportation due to extensive damages on roads and highways whereas urban localities have relieved from the disruption of movement of goods.

\subsection{Locality and Employment Generation}

Based on the sample observations and the analysis to determine the dependency between locality and employment generation, it is observed that they are independent since $p$ value is 0.151 in the Fishers exact test. In addition, $73 \%$ of the people responded that employability was substantially reduced irrespective of the urban rural divide. According to Directorate of industries and commerce (DIC) [4] which acts as the facilitator for growth of the MSME and traditional sectors in Kerala, 15,468 new MSME units operations started in Kerala in 2017-18 with a total investment of Rs. 124,961 lakh and generating employment for 51,244 persons. This emphasis the significance of MSMEs as employment generators for skilled, semi-skilled and unskilled labourers, keeping in mind the vast opportunity of employment that it offers in different level of manufacturing and service sector. It was understood that, employment generation has immensely suffered due to the mishap, significantly lowering even the existing jobs making many workers unemployed. This situation has pressured the entrepreneurs to drop many employees from the enterprises. As the result, socioeconomic problems have widened its extend in the society. It is also noteworthy that the employment loss was the one of the critical challenges suffered by the MSMEs irrespective of urban/rural difference.

\subsection{Insurance and Recovery}

Insurance provides a great relief at the time of unforeseen disasters and unanticipated losses. But it was appalling to know that $82 \%$ of the MSMEs have not subscribed to any type of insurances. It was later identified that the insurance amounts were not reasonable 
to recover from the losses that happened to the $72 \%$ of the people who have subscribed to the insurance. Red tapes after the occurrence of mishap have created an apprehension among the sector. Thus, it was found that insurance coverage has not helped the MSMEs to recover from the losses incurred due to flood.

\subsection{Ecological Concerns}

The survey that conducted comprised about $60 \%$ of its data from MSMEs from urban localities and $40 \%$ from the MSMEs of rural localities. In both these cases, one aspect that equally enhanced the impact of disaster was the unsuitable location of which it is situated, especially for manufacturing sector. For manufacturing enterprises, the topography of the place where it is functioning need to be particularly understood. It was observed that the enterprises functioning in ecologically sensitive areas were the worst affected by the flood. There were instances where the operation of certain enterprises blatantly violating the environmental laws and hurting the ecological stability of the region, particularly in rural localities. To curb this government scrutiny and vigilance need to be strengthening without discouraging the investors or undermining the growth prospects.

The properties which were affected by the floods including damaged goods made of plastic are raising concerns in environmental impact. It was requested to entrepreneurs to mention the method of disposal of damaged products after the flood and is plotted in Figure 2. Many people were reluctant to opine on this matter. The suggestions to curtail other devastating floods in future are given in Figure 3. Also, a combined plot showing the waste disposal method and at the same time their opinion about the environmental facts to prevent flood is shown in Figure 4. It is ironical to observe that the people who advocated for strengthening the existing norms for environmental protection were the same people who envisaged the method of dumping irresponsibly. Therefore, it is of prominent importance to educate them the strategy to minimise the environmental disturbance and impart innovative ideas to increase the growth of MSMEs.

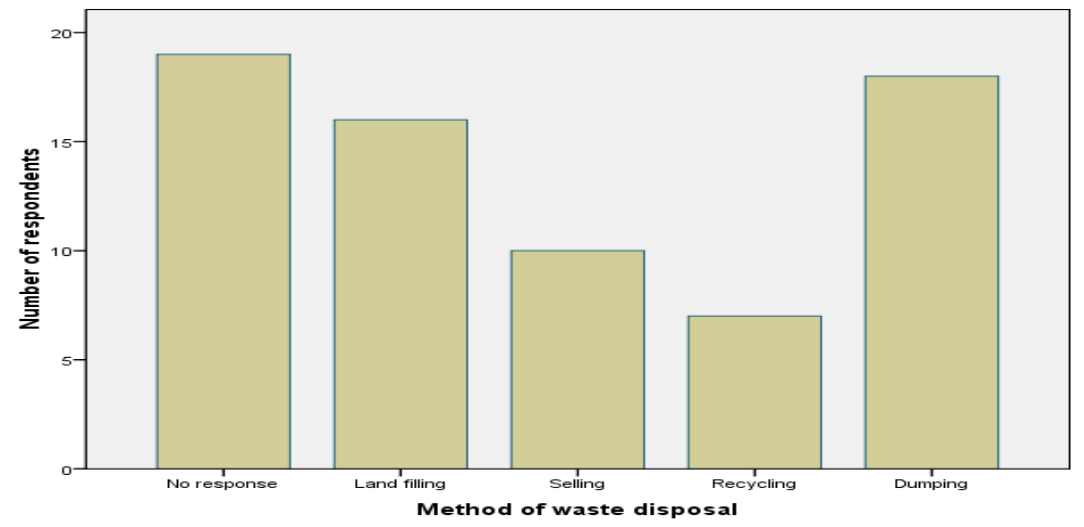

FIGURE 2. Methods of waste disposal. 


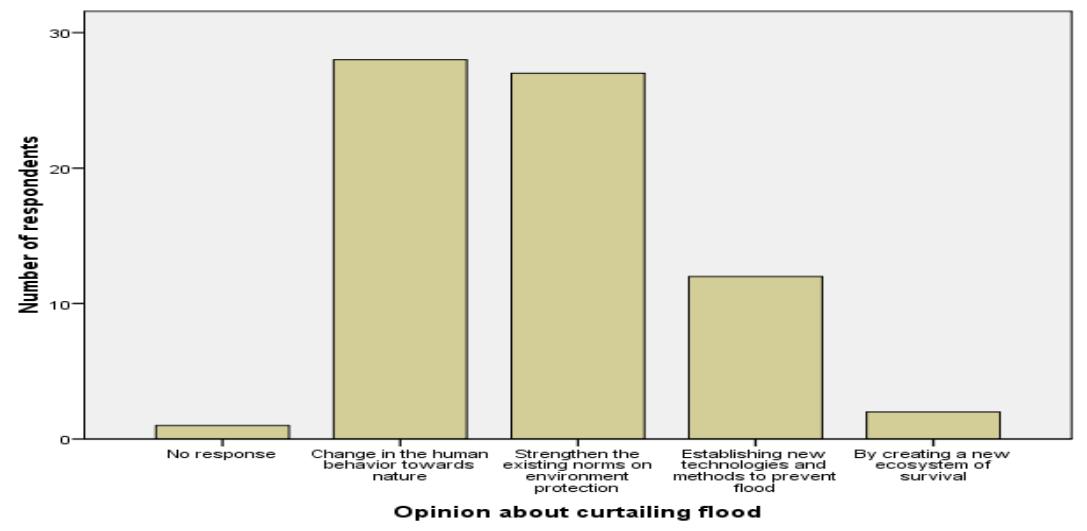

FIGURE 3. Suggestions for curtailing flood.

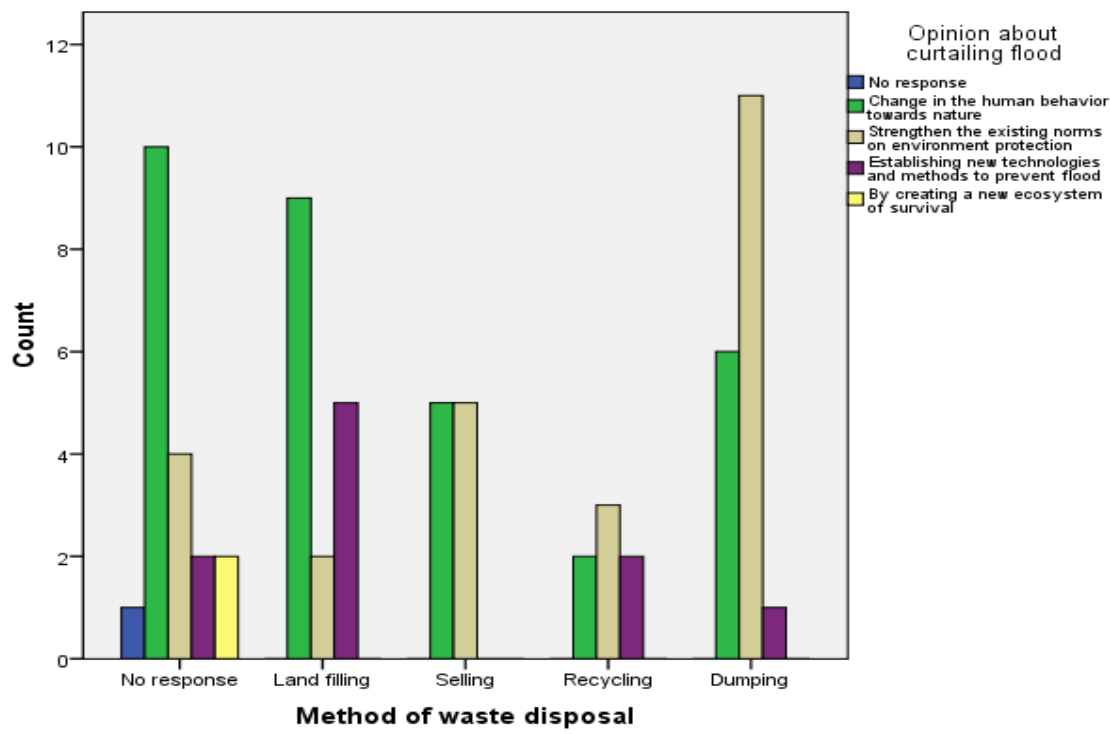

FIGURE 4. Waste disposal and suggestions for curtailing flood.

\subsection{Difference in Income}

For detecting whether the distribution of difference in income is the same across categories of locality, we have used Mann Whitney test and the $p$ value is 0.002 concluding that significant change was observed in the income among the two categories. It was logical to perceive based on the fact that customer arrival has declined in the urban areas, whereas it continued in the same phase in rural localities, purchasing capacity is found to be reduced in rural areas while it continued in the same level in urban localities. Similar changes were observed and reported above in other variables. Since the distribution of difference in income is not normal as shown in Figure 5, we use non-parametric test, Mann-Whitney $U$ test. 


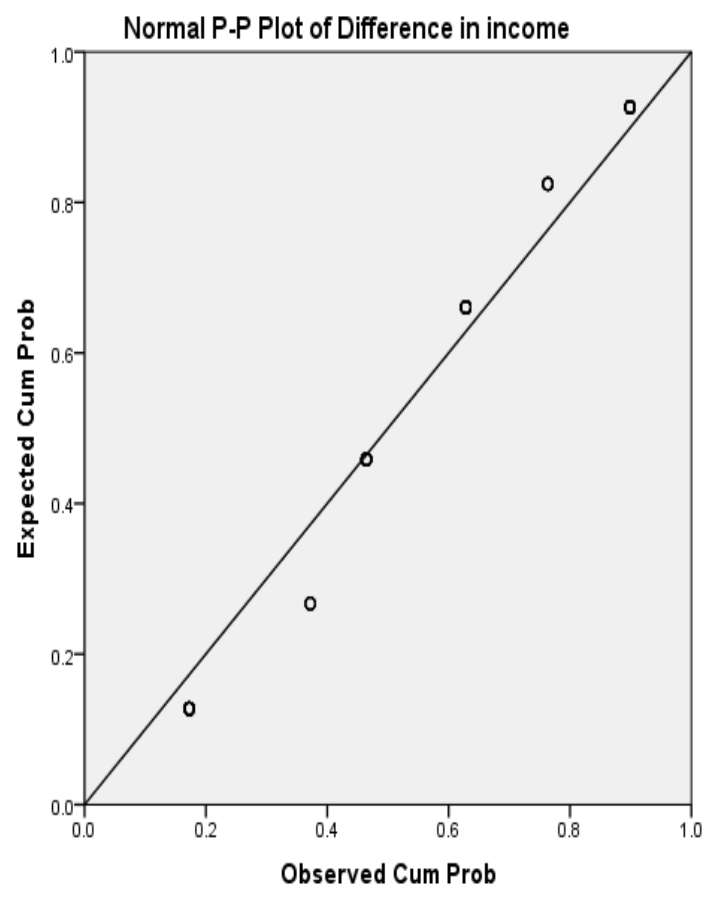

FIGURE 5. Plot for normality check.

\subsection{Severity of the Damages Caused}

The severity of the damages caused in the rural and the urban areas is studied using median test and the median rating differ for the locality as per the $p$ value is near zero. It was reflected from the opinion of the respondents that the severity of the rural localities was extremely intensive than that of the urban areas. It is noteworthy that the enterprises located in the ecologically sensitive zones (ESZ) were severely impacted by the cause of mishap. It should be particularly noted that the study delineated in the first section (Flood affected locality and impact of flood), the extent of the impact of flood is uniform and independent of urban/rural divide, whereas here we discuss the social-monetary damages that resulted due to course of devastation.

\subsection{Points Needed to be Considered for Formulation of New Policies}

After the elaborate study on the aftermaths of flood in the MSME sector, it was extrapolated that the MSMEs operating in the urban and rural localities were required to be dealt with distinctly different initiatives that satisfies their distinct needs. The very way of functioning, requirements and challenges were found to be diverse in different localities. It was also understood that the environmental concerns are needed to be addressed, with more scrutiny in granting the permission for the operation of MSMEs, curtailing permissions of functioning in ecologically sensitive areas. 


\section{Conclusion}

The study conducted analyzing the socio-economic aftermaths underscored the key ideas that customer arrival has declined in the urban areas while rural localities remained same. Purchasing capacity of customers decelerated in the rural localities whereas in urban localities approximate to normal. The expenditure incurred for the entrepreneurs as the result of the devastation was enormously hiked at the same time the employment generation experienced a significant dip in the sector. The overall function of the sector is slowly approaching the normalcy which can be facilitated by formalising the means of transportation especially in the rural localities. There is an urgent need for mandating the inclusion of insurance in the business and similar policy reforms by a detailed study which is a sine-qua-non for the reviving the potential of the MSME sector. The environmental concerns are indeed needed to be addressed with immediate effect considering the grave situation that many of the MSMEs violate the environmental norms, even the location of its operation were observed to be inappropriate, overlooking the topographical prospects. Proper education of waste disposal is imperative for reducing the challenges to the nature. Given the fact that the urban and rural localities undergoes in distinct perspective of functioning, it is imperative to formulate policies accordingly by considering different challenges and needs faced by them in a distinct manner. It is also important to revise the government financial assistance and insurance claim policy to secure the financial stability to genuine entrepreneurs who have experienced extreme devastation resulting from natural disasters. It was also perceived that specific consideration is needed for employment generation and enhancement of rural economy.

\section{Acknowledgement}

We acknowledge the support rendered by Sachin S., Fathima Fidha L. S., Ayisha Anan A. and Ayisha Thamanna P. in the data collection of this study.

\section{References}

1. Micro, small and medium enterprises in India: an overview. http://dcmsme.gov.in/ssiindia/ MSME_OVERVIEW09.pdf. Date accessed: 2009.

2. Floods devastate eastern part of Malappuram. https://www.thehindu.com/news/national/kerala/ floods-devastate-eastern-part-of-malappuram/article24647006.ece. Date accessed: 09/08/2018.

3. Rain continues to pound Malappuram. https://www.thehindu.com/news/national/kerala/raincontinues-to-pound-malappuram/article24696358.ece. Date accessed: 15/08/2018.

4. Government of Kerala. http://spb.kerala.gov.in/ER2018/index.php. Date accessed: 2018. 